\title{
The R/V MAURICE EWING JoIns THE U. S. ACADEMic Research FleEt
}

\author{
By Dennis E. Hayes
}

\begin{abstract}
Background
The R/V Robert D. Conrad, owned by the U. S. Nay and operated under charter by Lamont-Doherty Geological Observatory ( $L-D G O)$ of Columbia University for twenty-six years, had long been one of the premier ships for marine geology and geophysics (MG\&G) within the University-National Oceanographic Laboratory System (UNOLS) fleet. During this period the R/V Conrad carried numerous major research expeditions and sailed 1.25 million miles. Only one other vessel, the R/V Vema, ouned by Columbia University and retired in 1981, has surpassed the million mile research mark.
\end{abstract}

$\mathrm{I}_{\mathrm{N}}$ N RECENT YEARS, even though well-maintained, the R/V Conrad was unable to continue to meet today's more demanding mission requirements, and failures of obsolete engines and other key machinery had lead to regular repairs that were no longer cost effective. The Navy announced their intent to systematically retire the remaining Auxiliary General Oceanographic Research Class 3 (AGOR-3) vessels in the academic fleet and, as a consequence, the $R / V$ Conrad was designated to go out of service in 1989.

Both the MG\&G community in general and LDGO scientists in particular faced the unacceptable prospect of no longer having access to a UNOLS vessel with extensive multichannel seismic (MCS) capabilities and of losing one of the three UNOLS vessels capable of precision multibeam bathymetric swath mapping.

Somewhat earlier, the 1986 UNOLS study (see references) had pointed out that "the need to plan for new, more capable research ships to conduct scientific programs at sea has become virtually self evident." That report identified a generic profile of scientific capabilities for new/replacement ships for two categories of large vessels. High Endurance ships (250$300 \mathrm{ft}$ LOA) and Medium Endurance ships (200-250 LOA) (see the table on p. 38), and stated that all new replacement ships should have general purpose oceanographic capabilities. The report further noted that selected ships should have MCS capabilities and ice strengthening.

The new research programs planned included in the National Science Foundation (NSF) Global Geosciences Initiative had all supported the need for a variety of marine observations to be taken from large

Dennis E. Hayes, Lamont-Doherty Geological Observatory and Department of Geological Sciences. Columbia University. Palisades. New York 10964 vessels with medium to high endurance and highlatitude capabilities. Within the coming years, the World Ocean Circulation Experiment (WOCE), the Joint Global Ocean Flux Study (JGOFS), the Ridge Inter-Disciplinary Global Experiments (RIDGE), and continental margins programs all called for substantial increases in ship usage. Even with the addition of the Navy's AGOR-23 (to be operated by the University of Washington as the new R/N Thomas Thompson) and the upgrading of the R/V Knorr and R/V Melville, it was not clear that the resulting UNOLS fleet capability for global oceanographic research would be able to meet the planned research needs.

Mindful of the research needs and of the importance of finding a cost-effective way to replace the $R / V$ Conrad, L-DGO undertook an extensive search for a replacement vessel. The search was for a vessel that was near-new, with design specifications to meet the needs of new research programs (both general and MG\&G), and that would be available at a bargain price. The drop in oil prices had brought to the market several oil industry seismic vessels as possibilities. The Canadian Crown Corporation, Petro-Canada, wished to sell the Bernier, a five-year old, 239-foot geophysical exploration ship. In a buyer's market, we at L-DGO reasoned that an offer well under the appraisal price might be successful. In a competitive sealed-bid process in June 1988, Columbia was successful in obtaining a purchase option to buy the vessel for $\$ 6.5$ million, which involved a non-refundable $\$ 250,000$ deposit.

This purchase option, which was to expire December 1988, allowed Lamont scientists only a brief window of opportunity to prepare a comprehensive proposal to NSF. The proposal sought an NSF commitment to bring the Bernier into the academic fleet and outlined a plausible NSF repayment schedule for the purchase funds offered by Columbia to exercise the December 


\begin{tabular}{|c|c|c|c|}
\hline & $\begin{array}{l}\text { UNOLS High Endurance R } N \\
\text { (Monohull) }\end{array}$ & RN Ewing (Bemier as modified) & $\begin{array}{l}\text { UNOLS Medium Endurance RN } \\
\text { (Monohull) }\end{array}$ \\
\hline Size Range & Class I 250-300 ft & $239 \mathrm{ft}$ & Class I| 200-250 ft \\
\hline Endurance & $\begin{array}{l}\text { Sixty days (thirty-cruising; thirty- } \\
\text { working): } 15,000 \mathrm{~m} \text { total range at cruising. }\end{array}$ & $\begin{array}{l}\text { Sixty days; } 15,000 \mathrm{~m} \text { at } 12 \mathrm{kt} \\
\text { Forty days; } 12,000 \text { miles at } 14 \mathrm{kt}\end{array}$ & $\begin{array}{l}\text { Fifty days (twenty-five-cruising, twenty-five- } \\
\text { working); } 12.000 \mathrm{~m} \text { range at cruising. }\end{array}$ \\
\hline Cruising Speed & $15 \mathrm{kt}$ & $14 \mathrm{kt}$ & $14 \mathrm{kt}$ \\
\hline Seakeeping & $\begin{array}{l}15 \mathrm{kt} \text { through SS 4: } 13 \mathrm{kt} \text { through SS 5; } \\
8 \mathrm{kt} \text { through SS } 6\end{array}$ & $\begin{array}{l}14 \text { kt through SS 4; vessel routinely carries } \\
\text { out surveys at } 6 \text { kt up to SS } 6\end{array}$ & $\begin{array}{l}14 \mathrm{kt} \text { through SS 4, } 12 \mathrm{kt} \text { through SS } 5 \text {; } \\
8 \mathrm{kt} \text { through SS } 6\end{array}$ \\
\hline Station Keeping & $\begin{array}{l}\text { Dynamic positioning, best heading: SS } 5 \text {, } \\
3 \text { kt current; } 150 \text { ft maximum excursion }\end{array}$ & $\begin{array}{l}\text { Dynamic positioning, best heading: SS } 5,3 \mathrm{kt} \\
\text { current; < } 150 \mathrm{ft} \text { maximum excursion (Design spec) }\end{array}$ & Same as UNOLS Class I \\
\hline Precision Trackline & $\begin{array}{l}\text { Minimum } 2 \mathrm{kt} \text {; maximum lateral excursion } \\
150 \mathrm{ft} \text { at SS } 5\end{array}$ & $\begin{array}{l}\text { Articulated (Becker) Rudder } \\
\text { Same as UNOLS Class I }\end{array}$ & Same as UNOLS Class I \\
\hline Towing & $\begin{array}{l}\text { Capacity of } 10.000 \mathrm{lbs} \text { at } 6 \mathrm{kt} ; 25,000 \mathrm{lbs} \\
\text { at } 2.5 \mathrm{kt} \text { in SS } 5\end{array}$ & Routine towing of 18,000 lbs at 5 kts up to SS 6 & Same as UNOLIS Class I \\
\hline Science Accommodations & $\begin{array}{l}\text { Thirty to thirty-five scientific personnel in } \\
\text { two-person staterooms expandable to } \\
\text { forty using portable berthing vans }\end{array}$ & $\begin{array}{l}\text { Thirty scientific personnel in two-person } \\
\text { staterooms expandable to thirty-seven using } \\
\text { portable berthing vans }\end{array}$ & $\begin{array}{l}\text { Twenty to twenty-five scientific personnel in } \\
\text { two-person staterooms expandable to thirty } \\
\text { in portable berthing vans }\end{array}$ \\
\hline Deck Work Area & $\begin{array}{l}3,000 \mathrm{ft}^{2} \text { with contiguous } 12 \times 50^{\prime} \text { along-side } \\
\text { handling area; } 100 \text { tons disposable load }\end{array}$ & $\begin{array}{l}\text { Main deck } 2,950 \mathrm{ft}^{2} \text { with contiguous } 14^{\prime} \times 96^{\prime} \\
\text { area along side plus }>3,000 \mathrm{ft}^{2} \text { on } \mathrm{A} \text { and } \mathrm{B} \text { decks: } \\
100 \text { tons disposable load }\end{array}$ & $\begin{array}{l}2,000 \mathrm{ft}^{2} \text { with contiguous } 12^{\prime} \times 40^{\prime} \text { along-side } \\
\text { handling area; } 90 \text { tons disposable load }\end{array}$ \\
\hline Laboratory Area & $4,000 \mathrm{tt}^{2}$ plus four portable vans & $>3,000 \mathrm{ft}^{2}$ plus three vans & $3,000 \mathrm{ft}^{2}$ plus two portable vans with inside access \\
\hline Science Storage & $20,000 \mathrm{ft}^{3}$ & $\begin{array}{l}>13,000 \mathrm{ft}^{3} \text { (of which } 5, \overline{700 \mathrm{ft}^{3}} \text { is climate } \\
\text { controlled) }\end{array}$ & $\overline{15,000 \mathrm{ft}^{3}}$ \\
\hline Ice Strengthening & $\begin{array}{l}\text { ABS Class } 1 \text { B except ABS Class } 1 \text { AA when } \\
\text { specified as ice capable }\end{array}$ & $\begin{array}{l}\text { Hull- } \overline{A B S} \text { A1 lce Class } 1 \text { AA } \\
\text { Overall-ABS A1 lce Class } 1 A\end{array}$ & ABS Class $1 \mathrm{C}$ \\
\hline Acoustical Systems & $\begin{array}{l}\text { Sea Beam, } 3.5 \mathrm{kHz} \text { and } 12 \mathrm{kHz} \text { echo sounding } \\
\text { Doppler profiling bottom positioning }\end{array}$ & $\begin{array}{l}\text { Hydrosweep, } 3.5 \mathrm{kHz} \text { and } 12 \mathrm{kHz} \text { echo sounding } \\
\text { (Doppler profiler pending) }\end{array}$ & Same as UNOLS Class I \\
\hline Multi-Channel Seismics & $\begin{array}{l}\text { Selected vessels to carry seismic air } \\
\text { compressors for } 4,000 \mathrm{scfm} \text { at } 2,500 \mathrm{psi} \text {, } \\
\text { and a large array MCS system }\end{array}$ & $\begin{array}{l}\text { Seismic compressors for } 3,000 \text { scfm at } 2,500 \text { psi } \\
\text { plus } 400-800 \text { scfm with vans; } 120-240 \text { channel } \\
\text { digital MCS array; twenty airgun source array }\end{array}$ & $\begin{array}{l}\text { Selected vessels to carry seismic air compressors } \\
\text { for } 4,000 \mathrm{scfm} \text { at } 2,500 \text { psi and a large array } \\
\text { MCS system }\end{array}$ \\
\hline
\end{tabular}

Summary comparison of science mission requirements for new oceanographic ships. Selected datafrom UNOLS Fleet Replacement Committee, June 1986.

1988 purchase option. Following a rapid but comprehensive review process, the National Science Board (NSB) on the recommendation of the Division of Ocean Sciences endorsed the proposal in early December 1988.

The Lamont proposal for buying, reflagging and modifying this vessel totaled approximately $\$ 12$ million, and called for the ship to be operational by early to mid-1990. The savings over a new ship are considerable; a similarly configured and equipped new ship would cost $\$ 35-40$ million and would typically take a minimum of five to seven years from planning to the beginning of operations.

The NSF agreed to provide the modification and reflagging costs up-front and to repay the purchase price over a period not to exceed seven years. The financing and mechanics of replacing the Conrad with a larger, near-new, state-of-the-art oceanographic research vessel was made possible through extensive discussions, reviews and negotiations between Petro-
Canada, L-DGO and Columbia University, the National Science Foundation, and the UNOLS community. The Bernier was delivered to Fall River, Rhode Island, and the purchase consummated January 6 , 1989.

\section{Doing the Job}

Lamont-Doherty was now faced with the reality of translating plans and aspirations for transforming the Bernier into a state-of-the-art, general-purpose oceanographic vessel with enhanced MG\&G capabilities that would satisfy the UNOLS suite of capabilities for a large, medium-endurance research vessel. Furthermore, we needed to accomplish this in a timely and cost-effective manner. The cooperative agreement between NSF and Columbia University required that the Bernier be reflagged to the US and that the classification society be changed from Lloyds to the American Bureau of Shipping.

Following an extensive six-month planning period, specifications were compiled, priorities established, 


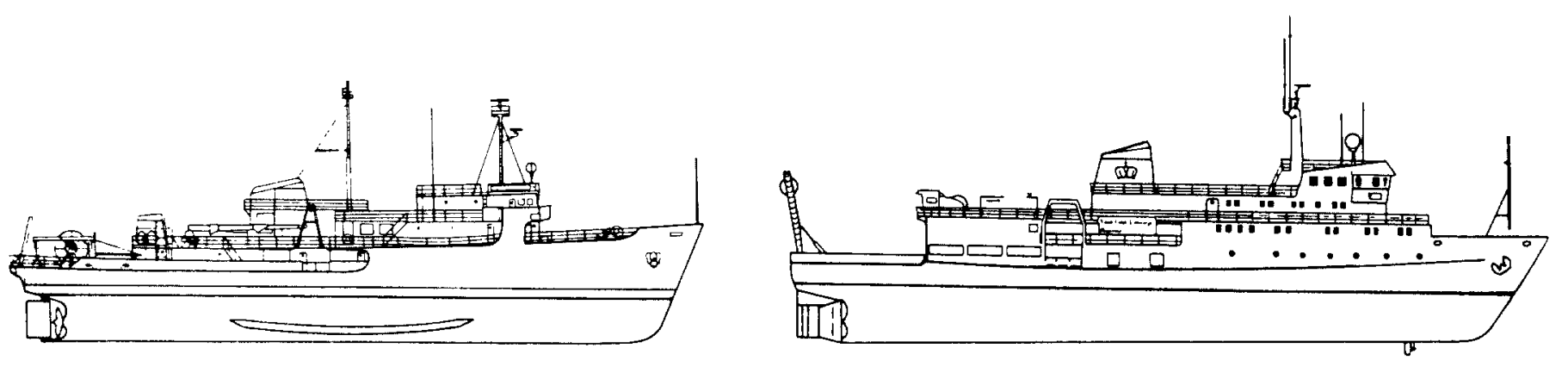

R/N Robert D. Conrad

R/N Maurice Ewing

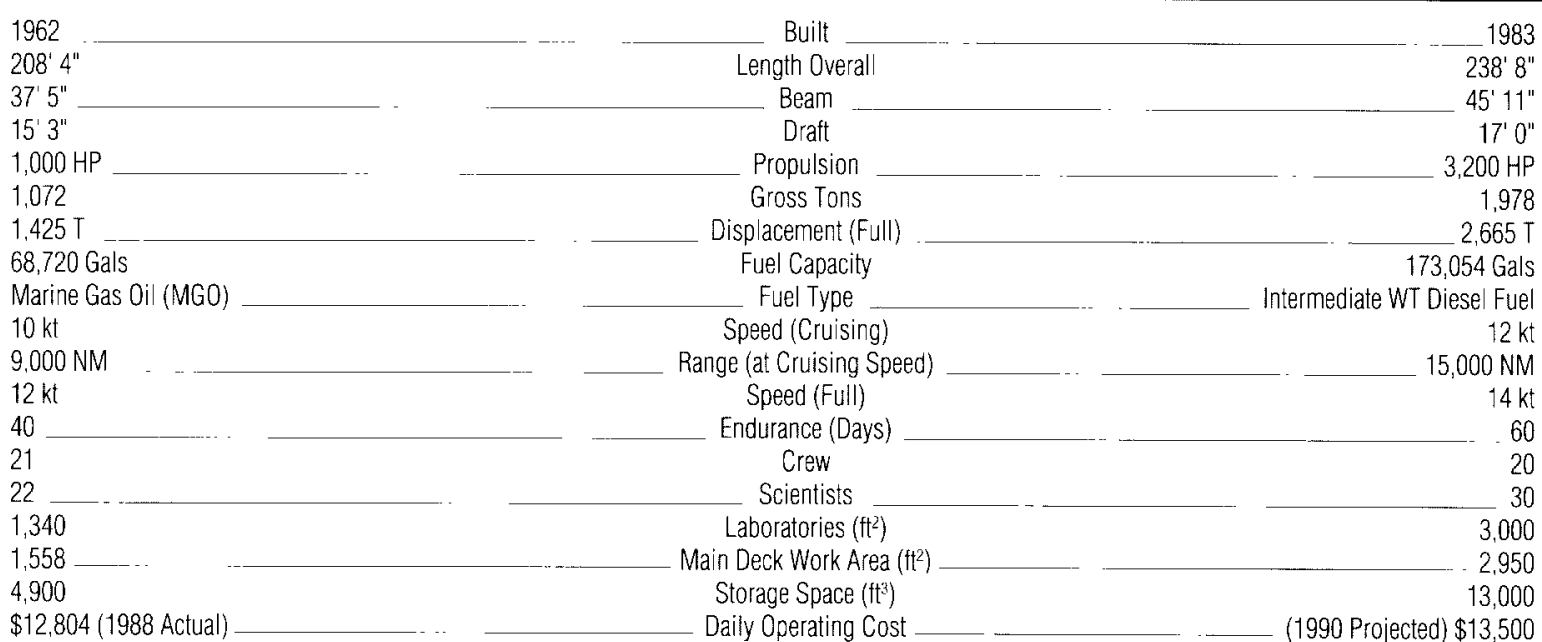

and bids were solicited from fourteen shipyards that had expressed interest. Equitable Shipyard (New Orleans, Louisiana) of the Trinity Marine Group was named as the successful bidder, and the vessel was delivered to the Equitable Yard in mid-November 1989. The interim period from January to October 1989 had allowed our own personnel to reflag the vessel while the vessel was berthed in Fall River, Rhode Island.

Our proposal to NSF had set forth a set of tasks and science modifications judged to be consistent with the general purpose utilization of the vessel and which would provide additional, enhanced MG\&G capability (including multichannel seismic and second-generation multibeam bathymetry). The goal was to both replace and improve on the capabilities that would be lost by the retirement of the R/V Conrad (see the table on this page for comparison), thereby meeting the ongoing needs of U.S. MG\&G scientists in academia. At the same time, we pledged to provide a comprehensive suite of capabilities on the vessel that would help meet the broad needs of the entire oceanographic community.
Toward this end and guided by the proposal reviews and the budget constraints set forth by NSF, a multidisciplinary Bernier-Lamont Advisory Committee ${ }^{\dagger}$ was established to review the generic science modifications outlined in the proposal, to identify additional important scientific and operational modifications, to assign priorities to such modifications, and to provide advice regarding the best way to implement the desired suite of changes. Input was also solicited from our colleagues within North East Consortium Research (NECOR). For example, the existing NECOR multi-beam subcommittee specifically addressed the pros and cons of several options that would ensure that multibeam capability could be available when the ship first went into research operations in early 1990.

A Bernier National Advisory Committee ${ }^{*+5}$ was also established to provide review and advice, both prior to submission of the modification package and following receipt of bids for the proposed shipyard work. The National Committee largely endorsed the conceptual modifications and helped prioritize the proposed modifications as developed by the Lamont Committee. 


\section{Summary of the Principal Modifications TO THE BERNIER}

- Structural removal of approximately $50 \%$ of the upper deck (previous helicopter deck) and the 'tween deck to provide about $1600 \mathrm{ft}^{2}$ of open space on the aft portion of the main working deck.

- Construction of five new labs on the main deck, including a $250 \mathrm{ft}^{2}, 12 \mathrm{ft}$ high staging area, wet lab, CTD lab, analytical lab and airgun shop.

- Addition of one deep-sea trawl winch, two hydro-winches and two new A-frames (one stern, one starboard midships).

- Installation of a Becker articulated rudder for improved maneuverability.

- Installation of two airgun array handing/ towing booms and capability to operate a twenty-gun array.
- Installation of a $90^{\circ}$ swath, second-generation (Hydrosweep) multibeam bathymetric system.

- Addition of eleven new berths.

- Installation of new heating/ventilation/air conditioning (HVAC) system and refrigeration compressors.

-Addition of new science and ship stores areas $\left(\sim 400 \mathrm{ft}^{2}\right)$

- Addition of 2' x 2' tie-downs on all working science deck areas.

- All modifications required by U.S. Coast Guard for reflagging and by the American Bureau of Shipping for classification.

\section{The Result}

The modifications of the Bernier have resulted in a versatile vessel, one that can accommodate most programs from every oceanographic discipline as well as multi-disciplinary programs. This versatility will help insure operational and logistic continuity and minimize costly, unproductive transits.

As laid out, the modified ship will comfortably accommodate a scientific party of thirty in two-person staterooms, each with either private bathroom or shared bathroom facilities between two adjacent rooms. These accommodations are generally more spacious than those of the existing, large UNOLS vessels. Lounge. offices, exercise and changing rooms, and public bathroom facilities are part of the overall accommodations of the vessel. The labs are conveniently located near the large open and covered main deck areas. In order to provide adequate open deck space, more than half of the original helicopter deck was removed. thereby preempting future helicopter landings on the vessel. The deck space is large enough so that water column programs, towing programs (e.g.. SeaMarc, large nets). and mooring deployments and retrievals can be easily implemented without the need to remove any MCS equipment. For those exceptionally demanding programs that require maximum possible deck space, the MCS reel and airgun booms can be removed to provide an even more open, unobstructed fantail.
The suitability of a particular vessel to meet the science needs can be distilled to a small number of basic criteria: space (labs, deck, storage, berthing), endurance, seakeeping. and overside and deck handling. The table on p. 38 summarizes and compares the capabilities of the ship, as modified, to the proposed capabilities of future UNOLS High and Medium Endurance vessels.

The Lamont Executive Committee recognized that the new vessel provided a unique opportunity to pay proper tribute to Maurice Ewing. Lamont's founder, first director, and world-renown pioneer in earth and ocean sciences. Permission was officially requested to rename the vessel the R/V Maurice Ewing, and NSF and Columbia University provided their enthusiastic endorsement of the proposed new name.

The modified Bernier, reborn as the R/V Maurice Ewing, clearly fulfills two vital needs: first, the need for a modern. high-endurance general purpose ship that can work in high latitudes; and. second, the need for an MG\&G-capable ship suitable to replace the R/V Conrad. It has the capabilities to be a major contributor to the collective U.S. fleet facilities required to perform future multi-disciplinary projects, such as the international RIDGE, WOCE, GOFS and others.

The R/V Ewing, a six-year old ship in excellent condition. is expected to serve the U.S. oceanographic research community for the next twenty-five years. 
$\mathrm{M}$ AURICE "DOC" EWING was the founder and first director of the Lamont Geological Observatory which came into existence in May 1950 with fifteen scientists comprising the staff. Ewing was a leader with boundless energy, extraordinary scientific insight, and the ability to draw out the best from his colleagues. The winner of virtually every major medal and award given in the geosciences and numerous honorary degrees, Ewing was arguably "the best" in this most vital era of earth/ocean sciences research. It is particularly fitting that in this year, the fortieth anniversary of Lamont-Doherty Geological Observatory (now with a staff in excess of five hundred), the new vessel be named in honor of W. Maurice Ewing, a true pioneer and leader in oceanographic research.

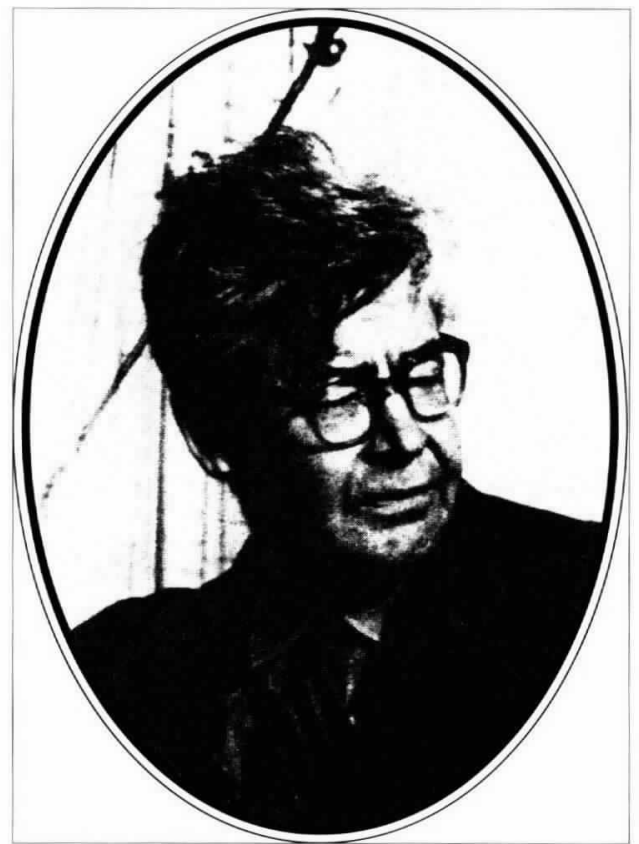

W. Maurice Ewing (1906-1974)
Moreover, the ship will be in full service in the critical next two years while retirement and reconditioning of other vessels within the existing UNOLS fleet would otherwise severely diminish U.S. research capabilities in ocean sciences.

The Ewing sailed from the shipyard June 15, 1990, and conducted fifteen days of seatrials and scientific shakedown. All systems are operational including the new Hydrosweep multibeam swath system and the new twenty-airgun seismic source array. The Becker articulated rudder appears to provide excellent maneuverability. As of September 1, 1990, the ship has successfully completed six weeks of simultaneous Hydrosweep, SeaMarc II and watergun seismic work in the North Atlantic supported by the Navy.

\section{A Creative Solution to the Problem of Fleet Replacement}

We at L-DGO have no doubts about the importance of the R/V Ewing in replacing the R/V Conrad, in avoiding an otherwise crippled MG\&G capability within the U.S. fleet, and in UNOLS having access to this ship for multipurpose oceanographic use. Given time, and the opportunity to serve the broad UNOLS community, we feel certain that the R/V Ewing's performance will justify the acquisition of this ship. In our view, the R/V Ewing represents a rare bargain because of its uniqueness in a limited marketplace for appropriate, nearly-new vessels at attractive price tags.
We are most pleased with the collective endorsement of the oceanographic community and NSF which was a prerequisite to our proceeding with the acquisition and modification of the Bernier.

L-DGO scientists demonstrated their belief that this acquisition was both necessary and sensible by making the commitment to investigate the appropriateness of this vessel as part of the future UNOLS fleet. Furthermore, a considerable institutional risk was assumed in making a non-refundable deposit of $\$ 250,000$ to acquire the option to purchase the vessel. We believe that Lamont-Doherty, acting in concert with NSF, has responded creatively to the consensus needs of the oceanographic community by taking the initiative to identify this opportunity, by securing the purchase option, and by establishing an innovative financing plan that has made the acquisition of this vital facility fiscally possible in these years of lean budgets.

\section{References}

A Unified Plan for Ocean Science: A Long-Range Plan for the Division of Ocean Sciences of the National Science Foundation. Advisory Committee on Ocean Sciences, August, 1987, 77 pp.

A Plan for Improved Capability of the University Oceanographic Research Fleet. UNOLS Fleet Replacement Committee, University-National Oceanographic Laboratory System, April, 1986, 65 pp.

UNOLS Fleet Improvement Plan. UNOLS Fleet Improvement Committee, University-National Oceanographic Laboratory System, May, 1990, 51 pp. $\square$ 